\title{
Gender Socialization: Differences between Male and Female Youth in India and Associations with Mental Health
}

\author{
Usha Ram, ${ }^{1,2}$ Lisa Strohschein, ${ }^{3}$ and Kirti Gaur ${ }^{2}$ \\ ${ }^{1}$ Centre for Global Health Research, St. Michael's Hospital, Toronto, Canada M5B 1W8 \\ ${ }^{2}$ Department of Public Health and Mortality Studies, International Institute for Population Sciences, Mumbai 400 088, India \\ ${ }^{3}$ University of Alberta, Edmonton, Canada T6G $2 \mathrm{H} 4$ \\ Correspondence should be addressed to Usha Ram; usharamagrawal@gmail.com
}

Received 28 June 2013; Accepted 11 April 2014; Published 27 April 2014

Academic Editor: Sandra D. Lane

Copyright (C) 2014 Usha Ram et al. This is an open access article distributed under the Creative Commons Attribution License, which permits unrestricted use, distribution, and reproduction in any medium, provided the original work is properly cited.

\begin{abstract}
This paper describes patterns of gender socialization among youth in India and evaluates how these patterns are associated with their mental health. Data come from the Youth in India: Situation and Needs Study $(N=44,769)$, a subnationally representative survey conducted during 2006-2008. Descriptive results underscored the gendered nature of socialization experiences, showing that male and female youth inhabit different social worlds. Female youth expressed more gender-egalitarian attitudes than male youth but reported greater restrictions to their independence than male youth. Male youth recognized more gender-discriminatory practices within their households than did the female youth. Poisson models revealed that female youth experienced more mental health problems when their households engaged in practices that favoured males over females, even as these same practices were associated with fewer mental health problems among male youth. Family violence and restrictions to independence were associated with mental health problems for both male and female youth. When males and females engaged in behaviours contravening sex-specific gender norms, there were corresponding increases in mental health problems for both sexes. Together, these findings suggest that gender inequality permeates family life in India, with corresponding consequences for the mental well-being of male and female youth.
\end{abstract}

\section{Introduction}

Listed as one of the eight Millennium Development Goals, the goal of ameliorating gender inequality and empowering women is well recognized as a critical tool for advancing population health, improving life chances, and bringing economic prosperity to low- and middle-income countries. Nonetheless, the obstacles to achieving this goal are daunting, given that gender inequality is often entrenched at all levels of society and, thus, requires changing both institutional structures and individual behaviours. That is, gendered norms govern what is deemed to be acceptable behaviour for the sexes and become the basis upon which girls and women throughout the world are systematically given fewer resources and opportunities than boys and men. When these restrictions are condoned by political and legal systems, women and girls become powerless to protect themselves from harm and are made vulnerable to disease, mental disorder, and death [1].

Linking these broad structural forces to individual health outcomes, however, requires researchers to pay greater attention to the microlevel processes that reproduce gender inequality. Moss [2] effectively bridged macro- and microlevel processes by identifying the household as an important site of gendered practices, whereby members favour male children but curb opportunities and resources for female children. Moreover, she suggested that researchers need to integrate these linkages in a way that acknowledges their geographic and historical specificity and accounts for different life stages. These ideas, combined with stress process theory, comprise the theoretical basis of the current study. 


\section{Theoretical Context}

While gender norms are broadly reinforced culturally and institutionally, it is within the household that children first learn about gender roles, equating maleness with power and authority and femaleness with inferiority and subservience. Boys learn how to exercise their authority over girls, whereas girls learn to submit. Consequently, gender socialization entails learning how to perform the behaviours that are consistent with one's gender. Moreover, both males and females are held to account for that performance, such that social sanctions follow when one engages in behaviour that deviates from what is expected for one's gender [3].

In India, households are a primary site in which male privilege and control over women are expressed. Despite being banned since 1994, selective abortion of female foetuses has become increasingly common and excess female mortality among children under age 5 years is seen in all parts of the country [4]. With few lifestyle options outside of marriage, girls are expected to marry. Yet daughters often prove to be financially burdensome for families as they must produce a sizeable dowry to the husband's family (the practice of dowry also remains widespread despite antidowry laws since the 1960s). Because verifying her chastity is a critical step in the marriage process, families are careful to regulate all aspects of their daughters' lives, controlling where they go and what they may do. From an early age, Indian girls are told that their proper place is in the home, fulfilling domestic duties and attending to the needs of men, whereas males learn that they are superior to women and must exercise authority over them [5].

Gender socialization occurs not only through the acquisition of gender-appropriate behaviours, but also through observing adults in the household, who are role models to children. When the household is characterized by family violence, children encounter another form of gender socialization. That is, children who witness fathers beating their mothers may become conditioned to accept violence in their relationships. Research in India has already established that violence is transmitted across generations, showing that married men who, as children, witnessed their father beating their mother were significantly more likely to condone and commit acts of violence against their own wives [6].

By positing that chronic strains and stressful life events threaten an individual's adaptive capacity, stress process theory provides a useful conceptual framework for linking patterns of gender socialization to the mental health of male and female youth in India [7]. First, stress process recognizes that stressors are generally harmful for the mental health of male and female youth. Thus, witnessing violence between parents and experiencing parental beatings are wellestablished predictors of mental health problems for both male and female youth $[8,9]$. Similarly, barriers that inhibit efforts to become more independent may create frustration and despair for youth, generating mental health problems regardless of gender. At the same time, however, it must be recognized that exposure to these stressors is not random, with females more likely to encounter barriers to independence because of their sex.
Second, it is likely that gender unequal practices within households produce their intended effect. When obstacles on the path to success are removed for males without regard to the cost for female children, male children should benefit while female children must work harder to keep up. Thus, in households where there is greater gender inequality, male youth should be expected to report fewer mental health problems. For female youth, living in a household with higher levels of gender inequality should be associated with greater mental health problems.

Finally, stress process recognizes that stressors arise when male and female youth engage in behaviour that is inconsistent with the expectations for their gender. For example, when male youth engage in domestic chores within the home, they are performing activities that are coded as feminine. In a society that clearly demarcates differences between the sexes, youth whose conduct is inconsistent with one's gender are at risk for social sanctions $[2,3]$. Thus, it is likely that performing sex-atypical tasks will be associated with greater mental health problems.

Although Indian society is marked by deep gender inequality, evidence linking gender socialization to mental health problems among youth is sorely lacking. Indeed, there are only a few studies that evaluate the links between gender socialization and youth mental health. In their analysis of predictors of common mental disorders in Indian youth aged 15-24 from state of Goa, Fernandes et al. [10] found that older youth who had reported being beaten by a teacher or family member in the past three months were at greater risk for common mental disorder. Pillai and colleagues [11] found that youth living in Goa who engaged in independent decision-making were less likely to be suicidal than youth who were unable to make independent decisions. The study further noted frequent verbal or physical abuse by parents, low parental support, and gender-based discrimination as significant predictors of mental health problems among Goan youth. This study, however, narrowly evaluated genderdiscriminatory practices with two questions asking whether the youth were treated differently or restrained from certain activities because of their gender.

This small amount of evidence on the Indian context lends support to the idea that gender socialization is linked to mental health problems in male and female youth. As such, the current study had two aims. The first goal was to describe differences in gender socialization by comparing youth-reported family experiences, independence, and gender role attitudes. It is hypothesized that male youth will experience more freedom and privileges than female youth in their households. Differences in recognizing genderdiscriminatory practices within households and gender egalitarian attitudes between male and female youth were also examined.

The second goal was to apply insights from stress process to test whether gender socialization was associated with mental health problems among male and female youth. Experiences that are stressful (exposure to family violence and restrictions to independence) are hypothesized to be equally detrimental to the mental health of male and female youth. Because gender-discriminatory practices afford 
advantages to males while simultaneously blocking opportunities for females, it was hypothesized that higher levels of gender-discriminatory practices within household will be associated with fewer mental health problems among male youth. Conversely, higher levels of gender-discriminatory practices should be associated with greater mental health problems among female youth. Finally, it was hypothesized that behaviours that contravene gender-specific norms, such as when females engage in male-typed chores and males perform tasks that are coded feminine, will be associated with worse mental health.

\section{Study Setting, Data, and Method}

Data for the present paper comes from the "Youth in India: Situation and Needs study," a subnationally representative study conducted in six states (Bihar, Jharkhand, Maharashtra, Rajasthan, Andhra Pradesh, and Tamil Nadu) undertaken between 2006 and 2008 [12]. The six states, selected for their different geographic and sociocultural backgrounds, represent $39 \%$ of the country's population.

The survey employed a multistage sampling design, initially selecting 300 primary sampling units (PSUs) in each state, split equally between rural and urban areas. In rural areas, the 2001 Census villages served as the sampling frame, with selection proceeding in two stages. First, villages were selected systematically from a stratified list (based on region, village size, caste composition, and female literacy), with selection probability proportional to size. The 150 PSUs selected were then ordered by district and taluka codes and numbered from 1 to 150 . Odd-numbered PSUs were designated for interviews with male youth and even-numbered PSUs for female youth. For urban areas, the 2001 Census list of wards (containing multiple census enumeration blocks (CEBs)) served as the sampling frame, with selection proceeding in three stages. First, wards were ordered by district and female literacy, and then 75 wards were selected systematically with probability proportional to size. Second, within each selected ward, CEBs were arranged by their administrative number and one CEB was selected proportional to size. This CEB was designated a male PSU and an adjacent $C E B$ to each selected male CEB was subsequently selected to be a female CEB, resulting in a total of 150 urban CEBs per state. The choice to designate male and female PSUs was guided by concern that the sensitive nature of some questions might lead to teasing, damaged reputations, or violence, if respondents became aware that similar questions were being asked of the opposite sex.

Once the PSUs were selected, household selection involved systematic sampling using a self-weighing design that took into account the target sample. There was no replacement for households that could not be contacted or refused to participate. Of 186,152 selected households, 174,037 agreed to participate, with a household response rate of 93.5\%. A household schedule was administered in participating households to determine whether there was an ageeligible youth living in the household. In households where there were multiple age-eligible youth, the Kish table was used to select one married and one unmarried youth, resulting in a maximum of two interviews per household. No replacement of a selected youth was allowed. In all, 45,555 male and female youth aged 15 to 24 participated, with individual response rates ranging from $84 \%$ to $90 \%$. Although two individuals could be interviewed in a given household, few households contributed more than one observation. Specifically, 1834 households contained two interviewed respondents and 43721 households contained one interviewed respondent, resulting in a trivial amount of clustering (1.04).

The survey tools were informed by existing surveys and an intensive presurvey with youth, parents, and key stakeholders, both before and after it was translated into four languages (Hindi, Marathi, Tamil, and Telugu, reflecting the major language groups of selected states). Approximately 75 locally trained and regularly supervised field investigators collected data over a six- to eight-month period. Informed consent was obtained from all respondents as well as parents of unmarried minor youth. To preserve confidentiality, consent forms were detached and stored separately from completed questionnaires. Complete details on all aspects of the survey are available elsewhere [12].

After removing youth who were missing on the key variables of interest, analysis was conducted on a final sample of 44,769 youth ( $98.3 \%$ of total sample).

3.1. Variables. The dependent variable, mental health problems, was assessed with the 12-item General Health Questionnaire inventory (GHQ-12), originally developed in the United Kingdom to screen for nonspecific psychiatric morbidity in the general population [13]. Youth were asked to indicate whether in the past month they had experienced a range of positive and negative emotions including feeling constantly under strain, worthless as person, unhappy and depressed, capable of making decisions, and able to enjoy normal activities. For each item, a negative emotional state was coded 1 and 0 otherwise. The items were summed to produce a score for each individual, with mental health problems increasing as scores, ranging from 0 to 12 , increase. The scale has strong psychometric properties with acceptable internal consistency $(\alpha=.76)$ [14] and has been widely used throughout India and demonstrates validity in the Indian population [15-18]. Although most studies impose a diagnostic cut-off, this study retained the dependent variable as a scale. Scales better reflect the full spectrum of variation in mental health whereas arbitrary cut-offs lose important information [19]. The decision was warranted given that the GHQ-12 is widely accepted as a screening tool for mental health problems but performs poorly in clinical settings as a diagnostic instrument. Importantly, prior research shows that diagnostic cut-offs for the GHQ-12 in the Indian population have low positive predictive value [17].

All models control for a wide range of demographic variables including age (in years), urban versus rural, region (north, west, and south), religious affiliation (Hindu, Muslim, and other), and caste (general castes, scheduled castes, scheduled tribe, other backward castes, and not known). Marital status has four categories: single/never married, married and 
currently living with spouse, married and currently not living with spouse, and married, no gauna (while marriage is a ritual union, gauna marks onset of conjugal life. It is a ceremony that takes place after a female attains sexual maturity and is common in northern India where child marriage continues). The work status of the youth in the last 12 months has four categories: engaged in paid work only, unpaid work only, both paid and unpaid work, and neither paid nor unpaid work. Years of schooling differentiates between less than 5 years (including illiterate and no formal education), 5 to 9,10 to 12 , and more than 12 years. Family type compares nonnuclear families (coded 1 ) with nuclear families (coded 0 ). Household wealth was based on 22 items assessing land ownership, access to basic sanitation, and assets such as vehicles and televisions, with values assigned to each item. Items were summed to produce a wealth index ranging from 0 to 54 and then divided into quintiles. Preliminary analysis showed better fit to the data with wealth quintiles than the continuous measure of household wealth; therefore, quintiles were retained.

Gender socialization in the present paper is conceptualized in terms of family experiences, independence, and gender role attitudes. Family experiences consisted of three variables: gender-discriminatory practices, performing chores inside and outside the home, and family violence. Gender-discriminatory practices asked youth whether or not compared with their opposite-sex siblings (or cousins for those who have no opposite sex sibling), their families of origin placed greater value on sons' education, allowed sons greater freedom, and expected less housework from sons. For each item, gender-discriminatory responses were coded 1 and 0 otherwise, summed to produce a score ranging from 0 to 3 and then converted into dummy variables.

Performing housework inside the home asked whether the youth had never, sometimes, or often cooked/cleaned in the household. Responses "sometimes" or "often" were coded 1 and 0 otherwise. Performing housework outside the home asked whether or not youth had never, sometimes, or often shopped (for vegetables or provisions) or performed other tasks such as collecting firewood, grazing (rural areas only). Responses "sometimes" or "often" were coded 1 and 0 otherwise, summed to produce a scale ranging from 0 to 2 and then converted into dummy variables.

Finally, two variables for family violence assessed whether youth had ever witnessed parental violence or received a beating from parent(s) since the age of 12, with affirmative responses coded 1 and 0 otherwise. Because the question about witnessing parental violence was only asked of youth with two living parents, those with at least one deceased parent were placed in a separate category. Youth who could not remember whether a parent had beaten them were assigned a separate category.

Independence assessed the youth's ability to make decisions, express an opinion, move about freely, and access money. Independent decision-making was assessed with three questions that asked whether youth alone decided on choosing friends, spending money, and buying clothes for themselves. Positive responses were coded 1 and 0 otherwise, summed with dummy variables constructed for each value. Expressing own opinion was assessed with two questions that asked whether youth could never, sometimes, or often express their opinion before elders (aside from parents) about things that concern them and confront a person who said/did wrong to them. Responses "sometimes" or "often" were coded as 1 and 0 otherwise and then coded with dummy variables. Freedom of movement differentiated between movement that was permitted either inside or outside one's village/neighbourhood. Unescorted mobility inside the village/neighbourhood asked whether youth could go unescorted to a shop/market, visit a friend/relative, or attend a program. Unescorted mobility outside the village/neighbourhood was based on three questions in which youth indicated that they could go unescorted to visit a friend/relative, or to a nearby village/neighbourhood for entertainment or attend a program. In both instances, positive responses were coded 1 and 0 otherwise, summed to produce a score ranging from 0 to 3 , with dummy variables constructed for each level. Finally, access to money asked if youth had a bank/post office account and whether they operated it. Responses were coded with dummy variables.

Gender egalitarian attitudes were assessed with seven questions (see Table 2 for items). Egalitarian responses were coded 1 and 0 otherwise, summed to produce a score ranging from 0 to 7 , with gender egalitarian attitudes increasing as score increase. Four dummy variables were constructed to compare scores $0-2,3,4$, and 5, with the omitted reference category, 6 or more.

Data were analyzed using Stata12. In preliminary analysis (not shown), correlation matrices confirmed that variables used in this study did not exhibit multicollinearity. Bivariate chi-square tests were used to test gender differences across all variables. Because the dependent variable, youth mental health problems, exhibited a marked positive skew, violating the assumptions of OLS regression, Poisson regression models were estimated instead. In a Poisson model, regression coefficients $(b)$ are interpreted as the logarithm of the ratio of the expected value $\left(e^{b}\right)$ before and after a one-unit change in an explanatory variable, with all other terms held constant. To take into account the complex multistage survey design including clustering, unequal probabilities of selection and nonresponse, analyses employed normalized sampling weights. The jack-knife method was used in multivariable Poisson models to produce appropriate variance estimators. Because the large number of cases in the sample increases the probability of a Type I error, coefficients are interpreted as statistically significant if $P<.01$.

\section{Results}

Table 1 presents sociodemographic profiles of male and female youth. More than half of youth were aged 15-19 and 29.5-30.3\% lived in urban areas. Most were Hindu; nearly half belonged to other backward castes. Reflecting an earlier age at marriage for females, fewer females (46.1\%) than males $(80.1 \%)$ were single/never married; conversely, more females than males were married and currently living with their spouse (47.2\% versus $17.5 \%)$. More females than males did not work (60.2\% versus $32.6 \%$ ). While $8.3 \%$ female and $11.1 \%$ 
TABLE 1: Sociodemographic characteristics of Indian youth by gender ("Youth in India: Situation and Needs Study," 2006-08 ( $N=$ 44769)).

\begin{tabular}{|c|c|c|}
\hline Characteristic & Female & Male \\
\hline \multicolumn{3}{|l|}{ Age } \\
\hline 15-19 & 52.5 & 53.2 \\
\hline $20-24$ & 47.5 & $46.8^{* * *}$ \\
\hline \multicolumn{3}{|l|}{ Place of residence } \\
\hline Rural & 70.5 & 69.7 \\
\hline Urban & 29.5 & $30.3^{* * *}$ \\
\hline \multicolumn{3}{|l|}{ Region } \\
\hline South & 36.0 & 33.0 \\
\hline West & 30.2 & 32.4 \\
\hline North & 33.8 & $34.6^{* * *}$ \\
\hline \multicolumn{3}{|l|}{ Religion } \\
\hline Hindu & 83.4 & 85.3 \\
\hline Muslim & 10.0 & 10.0 \\
\hline Other & 6.6 & $4.7^{* * *}$ \\
\hline \multicolumn{3}{|l|}{ Caste } \\
\hline General caste & 21.3 & 21.4 \\
\hline Scheduled caste & 20.5 & 19.7 \\
\hline Scheduled tribe & 7.0 & 9.3 \\
\hline Other backward castes & 50.4 & 48.8 \\
\hline Not known & 0.8 & $0.8^{* * *}$ \\
\hline \multicolumn{3}{|l|}{ Marital status } \\
\hline Single/never married & 46.1 & 80.1 \\
\hline Married, living with spouse & 47.2 & 17.5 \\
\hline Married, not living with spouse & 5.0 & 0.9 \\
\hline Married, no gauna & 1.7 & $1.5^{* * *}$ \\
\hline \multicolumn{3}{|l|}{ Work status } \\
\hline Paid only & 24.0 & 53.9 \\
\hline Unpaid only & 9.7 & 7.3 \\
\hline Both paid and unpaid & 6.1 & 6.2 \\
\hline Neither paid nor unpaid & 60.2 & $32.6^{* * *}$ \\
\hline \multicolumn{3}{|l|}{ Years of schooling } \\
\hline$<5$ years & 32.0 & 14.3 \\
\hline $5-9$ years & 37.8 & 43.5 \\
\hline $10-12$ years & 21.9 & 31.1 \\
\hline$>12$ years & 8.3 & $11.1^{* * *}$ \\
\hline \multicolumn{3}{|l|}{ Family type } \\
\hline Nuclear & 46.9 & 51.4 \\
\hline Nonnuclear & 53.1 & $48.6^{* * *}$ \\
\hline \multicolumn{3}{|l|}{ Wealth quintile } \\
\hline Quintile 1 (poorest) & 16.5 & 12.2 \\
\hline Quintile 2 & 18.3 & 18.8 \\
\hline Quintile 3 & 20.7 & 20.9 \\
\hline Quintile 4 & 22.3 & 25.0 \\
\hline Quintile 5 (wealthiest) & 22.2 & $23.1^{* * *}$ \\
\hline Mean (SD) mental health problems & $1.02(1.82)$ & $1.01(1.60)$ \\
\hline$N$ & 30704 & 14065 \\
\hline
\end{tabular}

male youth had more than 12 years schooling, more females (32.0\%) than males $(14.3 \%)$ had fewer than 5 years schooling. Slightly higher proportions of males than females lived in nuclear families and came from wealthier families. There were no gender differences in mental health problems.

Table 2 presents patterns of gender socialization for male and female youth. A higher proportion of males than females perceived gender-discriminatory practices within household. Significantly more females performed tasks inside the home than males; conversely, more males performed tasks outside home. Slightly more males than females reported witnessing parental violence $(22.8 \%$ versus $21.1 \%)$ and more than twice as many males (47.2\% versus $18.8 \%$ ) had experienced parental violence after the age of 12 . The majority of males decided alone on spending their money and buying clothes for themselves; in contrast, most females were unable to do so. Overall, few youth could often express their opinion to elders (aside from parents) or confront those who wronged them; even so, in each instance, this was more common for males than females. Freedom of movement, both inside and outside the village/neighbourhood, was largely permitted for males; however, females encountered greater restrictions on their mobility, particularly when going unescorted outside their village/neighbourhood. Access to money was extremely limited for both male and female youth, with males significantly more likely than females to own and operate a bank/post office account (13.4\% versus 6\%). Although both male and female youth were least likely to state that a woman does not need her husband's permission for most things $(28.4 \%$ and $35.0 \%$, resp.) and most likely to state that girls were as good as boys in studies (76.6\% and $81.2 \%$, resp.), significantly fewer males than females expressed egalitarian views.

The first set of columns in Table 3 presents the Poisson regression model for females. In preliminary bivariate analyses, nearly all control variables were significant; however, in the full model, only age, urban residence, and region retained statistical significance. Adjusted for other terms in the model, each additional year in age was associated with a $2 \%$ increase in mental health problems. Urban females reported fewer mental health problems than rural females. Mental health problems were significantly higher among those in northern and western regions (39-65\%) relative to those in southern regions.

Family life experiences were significant predictors of mental health problems among females; females whose families engaged in gender-discriminatory practices reported significantly more mental health problems than those whose families did not engage in such practices. Females who performed household tasks outside the home reported significantly more mental health problems than those who did not. Females who witnessed parental violence reported significantly more mental health problems than those who did not. Females who had been beaten by a parent after the age of 12 as well as those who could not remember being beaten reported significantly more mental health than those who had not been beaten.

Females who had independent decision-making in none or in only one of the three areas reported significantly more mental health problems than females who exercised 
TABLE 2: Gender socialization experiences ("Youth in India: Situation and Needs Study," 2006-08 $(N=44769))$.

\begin{tabular}{|c|c|c|}
\hline Indicators & Female & Male \\
\hline \multicolumn{3}{|l|}{ \% youth whose families: } \\
\hline Gave sons' education more importance & 33.2 & $46.3^{* * *}$ \\
\hline Allowed sons greater freedom & 52.2 & $68.6^{* * *}$ \\
\hline Expected less domestic work from sons & 51.0 & $52.4^{* * *}$ \\
\hline \multicolumn{3}{|l|}{ \% youth who never: } \\
\hline Cooked/cleaned in homes & 1.5 & $30.1^{* * *}$ \\
\hline Did any tasks outside home & 20.6 & $3.7^{* * *}$ \\
\hline \multicolumn{3}{|l|}{$\%$ youth who ever: } \\
\hline Witnessed parental violence & 21.1 & $22.8^{* * *}$ \\
\hline Beaten by parents after age 12 & 18.8 & $47.2^{* * *}$ \\
\hline \multicolumn{3}{|l|}{$\%$ youth able to make independent decision on: } \\
\hline Choosing friends & 90.4 & $94.5^{* * *}$ \\
\hline Spending money & 49.2 & $72.4^{* * *}$ \\
\hline Buying clothes and so on for self & 33.3 & $65.7^{* * *}$ \\
\hline \multicolumn{3}{|l|}{$\%$ youth who are often able to: } \\
\hline Express opinion before elders (aside from parents) & 30.4 & $38.4^{* * *}$ \\
\hline Confront the person who wronged them & 34.0 & $43.3^{* * *}$ \\
\hline \multicolumn{3}{|l|}{$\%$ youth with unescorted mobility inside village/neighborhood: } \\
\hline A shop/market & 66.9 & $94.9^{* * *}$ \\
\hline Visit a friend/relative & 63.0 & $89.9^{* * *}$ \\
\hline Attend any program & 17.3 & $75.8^{* * *}$ \\
\hline \multicolumn{3}{|l|}{ \% youth with unescorted mobility outside village/neighborhood: } \\
\hline Visit a friend/relative & 22.3 & $82.0^{* * *}$ \\
\hline Attend any program & 6.1 & $67.1^{* * *}$ \\
\hline Entertainment & 5.1 & $66.1^{* * *}$ \\
\hline \multicolumn{3}{|l|}{ \% youth who: } \\
\hline Owned and operated account & 6.0 & $13.4^{* * *}$ \\
\hline Owned but did not operate account & 5.2 & $1.4^{* * *}$ \\
\hline \multicolumn{3}{|l|}{ \% youth who believe: } \\
\hline Educating girls is as important as educating boys & 77.8 & $62.6^{* * *}$ \\
\hline Husband alone should not decide on spending household money & 74.7 & $67.0^{* * *}$ \\
\hline Girls should be allowed to decide when they want to marry & 73.7 & $57.3^{* * *}$ \\
\hline Woman does not need husband's permission for most things & 35.0 & $28.4^{* * *}$ \\
\hline Girls are usually as good as boys in studies & 81.2 & $76.6^{* * *}$ \\
\hline Boys should do as much domestic work as girls & 44.3 & $43.0^{* * *}$ \\
\hline Girls do not deserve to be teased if dressed provocatively & 57.7 & $46.2^{* * *}$ \\
\hline$N$ & 30704 & 14065 \\
\hline
\end{tabular}

Note: ${ }^{* * *} P<.001$.

independent decision-making in all three areas. Females who could neither confront nor express their opinion reported mental health problems that were, on average, $15 \%$ higher than those who could do both. Mental health problems were significantly higher for females who could go unescorted to one of three places inside their village/neighbourhood and for females who could not go to any place inside their village/neighbourhood unescorted relative to females with no restrictions. Compared with females who subscribed to egalitarian gender role attitudes on six or more items, females who subscribed to egalitarian attitudes on four or fewer items reported significantly more mental health problems.
The second set of columns in Table 3 presents the Poisson regression model for male youth. As was the case with models for female youth, many control variables were significant in bivariate models; however, in multivariable analyses, not all remained significant. Each additional year of age was associated with a $3 \%$ increase in mental health problems for male youth. Urban males reported 18\% fewer mental health problems than rural males, whereas males in western and northern regions reported 30-45\% more mental health problems than those in southern regions. Males from a scheduled tribe reported significantly more mental health problems than general castes males. Compared to single/never married 
TABLE 3: Poisson regression model for gender socialization and mental health problems among females and males ("Youth in India: Situation and Needs Study," 2006-08 $(N=44769))$.

\begin{tabular}{|c|c|c|c|c|c|c|}
\hline \multirow{2}{*}{ Indicators } & \multicolumn{3}{|c|}{ Females $(N=30704)$} & \multicolumn{3}{|c|}{ Males $(N=14065)$} \\
\hline & $b$ & (se) & $e^{b}$ & $b$ & (se) & $e^{b}$ \\
\hline Age & 0.02 & $(0.01)^{* *}$ & 1.02 & 0.03 & $(0.01)^{* * *}$ & 1.03 \\
\hline \multicolumn{7}{|l|}{ Residence $($ ref. $=$ rural $)$} \\
\hline Urban & -0.22 & $(0.03)^{* * *}$ & 0.81 & -0.20 & $(0.04)^{* * *}$ & 0.82 \\
\hline \multicolumn{7}{|l|}{ Region (ref. = south) } \\
\hline West & 0.50 & $(0.04)^{* * *}$ & 1.65 & 0.37 & $(0.05)^{* * *}$ & 1.45 \\
\hline North & 0.33 & $(0.04)^{* * *}$ & 1.39 & 0.26 & $(0.05)^{* * *}$ & 1.30 \\
\hline \multicolumn{7}{|l|}{ Religion (ref. $=$ Hindu) } \\
\hline Muslim & -0.01 & $(0.04)$ & 0.99 & 0.05 & $(0.06)$ & 1.05 \\
\hline Other & -0.01 & $(0.05)$ & 0.99 & 0.07 & $(0.07)$ & 1.07 \\
\hline \multicolumn{7}{|l|}{ Caste $($ ref. $=$ general caste $)$} \\
\hline Scheduled castes & 0.09 & $(0.04)$ & 1.09 & 0.05 & $(0.06)$ & 1.05 \\
\hline Scheduled tribe & 0.08 & $(0.05)$ & 1.08 & 0.18 & $(0.06)^{* *}$ & 1.19 \\
\hline Other backward castes & -0.01 & $(0.03)$ & 0.99 & 0.08 & $(0.05)$ & 1.08 \\
\hline Not known & 0.06 & $(0.13)$ & 1.06 & 0.25 & $(0.21)$ & 1.28 \\
\hline \multicolumn{7}{|l|}{ Marital status (ref. $=$ single/never married) } \\
\hline Married, living with spouse & -0.03 & $(0.04)$ & 0.97 & -0.19 & $(0.06)^{* *}$ & 0.83 \\
\hline Married, not living with spouse & -0.02 & $(0.07)$ & 0.98 & 0.23 & $(0.16)$ & 1.26 \\
\hline Married, no gauna & 0.00 & $(0.09)$ & 1.00 & -0.38 & $(0.15)^{* *}$ & 0.68 \\
\hline \multicolumn{7}{|l|}{ Work status (ref. $=$ paid only) } \\
\hline Unpaid only & 0.00 & $(0.05)$ & 1.00 & -0.08 & $(0.07)$ & 0.92 \\
\hline Both paid and unpaid & -0.11 & $(0.06)$ & 0.90 & 0.19 & $(0.07)^{* *}$ & 1.20 \\
\hline Neither paid nor unpaid & -0.05 & $(0.03)$ & 0.95 & 0.03 & $(0.05)$ & 1.04 \\
\hline \multicolumn{7}{|l|}{ Years of schooling (ref. = >12 years) } \\
\hline $10-12$ years & 0.05 & $(0.03)$ & 1.05 & -0.10 & $(0.05)$ & 0.90 \\
\hline $5-9$ years & -0.09 & $(0.05)$ & 0.91 & -0.15 & $(0.06)$ & 0.86 \\
\hline$<5$ years & -0.12 & $(0.07)$ & 0.89 & -0.10 & $(0.08)$ & 0.90 \\
\hline \multicolumn{7}{|l|}{ Family type (ref. = nuclear) } \\
\hline Nonnuclear & 0.02 & $(0.03)$ & 1.02 & 0.08 & $(0.03)$ & 1.08 \\
\hline \multicolumn{7}{|l|}{ Wealth quintile (ref. = Q5, wealthiest) } \\
\hline Quartile 4 & -0.08 & $(0.04)$ & 0.92 & 0.12 & $(0.05)$ & 1.13 \\
\hline Quartile 3 & -0.08 & $(0.04)$ & 0.92 & 0.16 & $(0.06)^{* *}$ & 1.17 \\
\hline Quartile 2 & -0.06 & $(0.05)$ & 0.94 & 0.18 & $(0.06)^{* *}$ & 1.19 \\
\hline Quartile 1 (poorest) & -0.11 & $(0.05)$ & 0.90 & 0.26 & $(0.07)^{* * *}$ & 1.30 \\
\hline \multicolumn{7}{|c|}{$\begin{array}{l}\text { Families discriminated between sons and daughters in education, freedom to roam, and } \\
\text { household work (ref. = no gender-discrimination in all } 3 \text { matters) }\end{array}$} \\
\hline Gender-discrimination in 1 matter & 0.30 & $(0.04)^{* * *}$ & 1.35 & -0.12 & $(0.05)$ & 0.89 \\
\hline Gender-discrimination in 2 matters & 0.31 & $(0.04)^{* * *}$ & 1.36 & -0.28 & $(0.05)^{* * *}$ & 0.76 \\
\hline Gender-discrimination in all 3 matters & 0.42 & $(0.04)^{* * *}$ & 1.52 & -0.24 & $(0.05)^{* * *}$ & 0.79 \\
\hline \multicolumn{7}{|c|}{ Youth did household chores inside home (ref. $=$ never) } \\
\hline Performed housework & 0.01 & $(0.11)$ & 1.01 & 0.15 & $(0.04)^{* * *}$ & 1.16 \\
\hline \multicolumn{7}{|c|}{$\begin{array}{l}\text { Youth did household chores outside home (ref. = neither shopped nor did other outside } \\
\text { chores) }\end{array}$} \\
\hline Either shopped or did other outside chores & 0.10 & $(0.03)^{* *}$ & 1.11 & -0.15 & $(0.09)$ & 0.86 \\
\hline Both shopped and did other outside chores & 0.14 & $(0.04)^{* * *}$ & 1.15 & -0.31 & $(0.08)^{* * *}$ & 0.73 \\
\hline \multicolumn{7}{|l|}{ Ever witnessed violence between parents $($ ref. $=$ no $)$} \\
\hline Yes & 0.33 & $(0.03)^{* * *}$ & 1.39 & 0.25 & $(0.04)^{* * *}$ & 1.28 \\
\hline Not asked-either/both parents deceased & 0.19 & $(0.04)^{* * *}$ & 1.20 & 0.07 & $(0.05)$ & 1.07 \\
\hline
\end{tabular}


TABLE 3: Continued.

\begin{tabular}{|c|c|c|c|c|c|c|}
\hline \multirow{2}{*}{ Indicators } & \multicolumn{3}{|c|}{ Females $(N=30704)$} & \multicolumn{3}{|c|}{ Males $(N=14065)$} \\
\hline & $b$ & (se) & $e^{b}$ & $b$ & (se) & $e^{b}$ \\
\hline \multicolumn{7}{|l|}{ Ever experienced parental violence after age $12($ ref. $=$ no $)$} \\
\hline Yes & 0.24 & $(0.03)^{* * *}$ & 1.27 & 0.12 & $(0.03)^{* *}$ & 1.12 \\
\hline Do not remember & 0.30 & $(0.11)^{* *}$ & 1.35 & -0.13 & $(0.26)$ & 0.88 \\
\hline \multicolumn{7}{|c|}{$\begin{array}{l}\text { Able to make independent decision-choosing friends, spending money, buying clothes, } \\
\text { and so on (ref. = yes, all 3) }\end{array}$} \\
\hline Yes, 2 of 3 items & 0.05 & $(0.04)$ & 1.05 & 0.04 & $(0.04)$ & 1.04 \\
\hline Yes, 1 of 3 items & 0.13 & $(0.04)^{* * *}$ & 1.14 & 0.02 & $(0.05)$ & 1.02 \\
\hline Unable to make independent decision on any item & 0.37 & $(0.05)^{* * *}$ & 1.45 & 0.26 & $(0.10)$ & 1.29 \\
\hline \multicolumn{7}{|l|}{ Able to often express/confront (ref. $=$ express and confront) } \\
\hline Either express or confront & 0.06 & $(0.04)$ & 1.06 & 0.37 & $(0.05)^{* * *}$ & 1.44 \\
\hline Neither express nor confront & 0.14 & $(0.03)^{* * *}$ & 1.15 & 0.22 & $(0.04)^{* * *}$ & 1.25 \\
\hline \multicolumn{7}{|l|}{ Unescorted mobility inside $\mathrm{V} / \mathrm{N}$ (ref. = yes, all 3 places) } \\
\hline Yes, only to 2 places & -0.06 & $(0.04)$ & 0.94 & 0.02 & $(0.06)$ & 1.02 \\
\hline Yes, only to 1 place & 0.29 & $(0.05)^{* * *}$ & 1.34 & 0.22 & $(0.08)^{* *}$ & 1.25 \\
\hline No, cannot go to any place & 0.24 & $(0.04)^{* * *}$ & 1.27 & 0.55 & $(0.09)^{* * *}$ & 1.73 \\
\hline \multicolumn{7}{|l|}{ Unescorted mobility outside $\mathrm{V} / \mathrm{N}$ (ref. = Yes, all 3 places $)$} \\
\hline Yes, only to 2 places & 0.18 & $(0.10)$ & 1.20 & 0.21 & $(0.06)^{* * *}$ & 1.23 \\
\hline Yes, only to 1 place & 0.08 & $(0.09)$ & 1.08 & 0.09 & $(0.06)$ & 1.09 \\
\hline No, cannot go to any place & -0.02 & $(0.09)$ & 0.98 & 0.03 & $(0.07)$ & 1.03 \\
\hline \multicolumn{7}{|l|}{ Access to money (ref. $=$ owns and operates account) } \\
\hline Owns but does not operate account & -0.04 & $(0.08)$ & 0.96 & 0.28 & $(0.11)$ & 1.32 \\
\hline Does not own an account & -0.02 & $(0.06)$ & 0.98 & 0.16 & $(0.06)^{* *}$ & 1.17 \\
\hline \multicolumn{7}{|l|}{ Egalitarian gender role attitudes (ref. $=6$ or more items) } \\
\hline Gender-equitable on 5 items & 0.09 & $(0.04)$ & 1.09 & 0.16 & $(0.07)$ & 1.18 \\
\hline Gender-equitable on 4 items & 0.18 & $(0.04)^{* * *}$ & 1.20 & 0.29 & $(0.07)^{* * *}$ & 1.34 \\
\hline Gender-equitable on 3 items & 0.24 & $(0.04)^{* * *}$ & 1.27 & 0.37 & $(0.07)^{* * *}$ & 1.44 \\
\hline Gender-equitable on $0-2$ items & 0.34 & $(0.05)^{* * *}$ & 1.41 & 0.38 & $(0.07)^{* * *}$ & 1.46 \\
\hline
\end{tabular}

Notes: ${ }^{* *} P<.010 ;{ }^{* * *} P<.001 ; \mathrm{V} / \mathrm{N}$ : village/neighborhood.

males, married males currently living with their spouse and those married but no gauna reported significantly fewer mental health problems. Relative to males from the wealthiest households, males from the lowest three household wealth quintiles reported significantly more mental health problems.

Males who grew up in families engaging in genderdiscriminatory practices that favoured sons reported significantly fewer mental health problems than those who grew up in families that did not engage in gender-discriminatory practices. Males who engaged in domestic tasks inside the home had on average $16 \%$ more mental health problems than those who did not. Males who did domestic tasks outside home reported $27 \%$ fewer mental health problems than those who did not. Males who witnessed parental violence reported on average $28 \%$ more mental health problems than those who never witnessed parental violence. Male youth who had ever been beaten by parent(s) after the age of 12 reported on average $12 \%$ more mental health problems than those who had not been beaten.

Males who could either express their opinions or confront others and males who could neither express nor confront reported significantly more mental health problems than those who could do both. Compared to males with no restrictions on their mobility inside their village/neighbourhood, mental health problems were $25 \%$ higher for males who could go unescorted to one of the three places and 73\% higher for males who could not go unescorted to any place. Males who were able to go to two of the three places outside their village/neighbourhood reported significantly more mental health problems than males with unlimited mobility. Males with no access to money reported significantly more mental health problems than those who had both access and control. Males who subscribed to four or fewer egalitarian gender role attitudes reported significantly more mental health problems than those who subscribed to six or more.

\section{Discussion}

Poised to have one of the largest pools of young people in the world, youth will play a pivotal role in building the future of the Indian society. As youth enter adult roles and 
prepare to parent the next generation, there is a pressing need to understand how gender socialization has shaped their experiences and how these experiences are connected to their mental well-being. As the first to address these issues in the Indian context, the current study makes the following contributions.

First, findings confirm that fewer female youth in India enjoy the same privileges afforded male youth, providing a comprehensive portrait of their family lives. Both male and female youth indicated that gender-discriminatory practices within their households were common, with sons given preference in education, freedom to roam, and household tasks. In all instances, male youth were more likely to identify gender-discriminatory practices within households than female youth. This is a troubling finding as it suggests that female youth lack awareness that they are disadvantaged by their gender.

Female youth also faced greater barriers to independence than male youth as they were less likely to engage in independent decision-making in their day-to-day lives, faced greater restrictions on their mobility, and lacked access to money. To the extent that these are key stepping stones for success in adulthood, observed deficits among female youth are likely to limit upward mobility and contribute to persisting gender inequalities throughout adulthood.

Despite household practices that favoured male youth over female youth, mobility, independent decision-making, and access to money were not universal among male youth. Fewer than half of male youth could express their opinion to elders (aside from parents) or confront others who had wronged them. Most male youth did not have access to money. Thus, there is considerable room for improving independent behaviour among male youth as well.

Finally, a greater proportion of females than males subscribed to gender-egalitarian attitudes. This finding is interesting when contrasted with the finding that a greater proportion of males than females identified gender-discriminatory practices within households. What this suggests is that while males generally recognize that females are not afforded the same privileges as males, they do not see these arrangements as problematic.

A second contribution of this study is that it confirms links between gender socialization and youth mental health. Indeed, drawing on stress process, support was found for all three hypotheses linking gender socialization to the mental health of male and female youth. First, the results of this study show that stressful experiences are harmful to the mental health of both male and female youth. Consistent with prior research $[10,20]$ youth experiencing a parental beating reported more mental health problems than those who did not experience violence at the hands of their parents. Similarly, restrictions to youth mobility and expressing themselves to others were associated with mental health problems for both male and female youth. Although females face more barriers to independence than males, greater independence is linked to better mental health for both sexes.

Importantly, this study shows the association between gender-discriminatory practices and mental health operates in different directions for male and female youth. For male youth, the higher the level of household genderdiscriminatory practices, the lower the amount of mental health problems. In contrast, females reported higher mental health problems as the number of gender-discriminatory practices in their households increased. The household environment emerges as a key setting in which gender inequality becomes insinuated in the fabric of social life, with corresponding influences on mental health and well-being. As such, this study is able to connect the microlevel practices of the household to the diverging destinies of male and female youth and their mental well-being [2].

Finally, consistent with the hypothesis that violating gender norms would be associated with worse mental health, performing household tasks inside the home was associated with more mental health problems for male youth, whereas female youth who performed chores outside the home reported more mental health problems (gender consistent behaviour in these areas was unrelated or associated with better mental health). To the extent that gender boundaries are rigorously policed in Indian society, it is clear that engaging in gender-inconsistent behaviour was associated with mental health problems for both male and female youth.

Although not the focus of this study, results also affirm sociodemographic characteristics including caste and wealth quintiles as predictors of mental health [21]. Given that most demographic variables were associated with mental health problems in bivariate analyses, the social patterning of mental health problems remains an important upstream factor that requires further investigation in the Indian context.

\section{Recommendations}

Our analysis underscores that gender-discriminatory practices and lack of independence are linked to youth mental health, revealing an unmet need for programs that are inclusive of male and female youth, their parents, and key community players. Such programs should encourage them to question gender stereotypes and develop independent thinking and behaviour, which are necessary for a healthy transition to adulthood. Although the Government of India has made efforts $[22,23]$ to develop mental health policies, there is a need for a comprehensive mental health program that targets youth and reaches out to youth living in vulnerable family environments.

\section{Limitations}

First, data for the analysis come from six states in India. Although this captures well-known social-cultural diversity within the country, it excludes unique aspects of states in northeastern India. A population-based survey of Indian youth does not yet exist, but should be a goal of future research. Furthermore, the data were cross-sectional, limiting causal inference. In addition, the gender composition of the household could not be established, making it difficult to know its role in gender socialization and mental health outcomes. Thus, instead of between-family comparisons, future studies should incorporate a within-families approach 
to better understand the ways in which male and female youth in the same household are affected by gender-discriminatory practices [24].

Despite these shortcomings, this study provides critical insight into the lives of a contemporary cohort of Indian youth, revealing the extent to which female youth are at disadvantage due to their gender. With far less freedom and independence relative to male youth, female youth are poorly equipped to enter adult roles with the skills they will need to be successful adults in the twenty-first century. It also clear that these social arrangements serve the interests of men. Indeed, by organizing households in ways that reinforce and promote gender-discriminatory practices within households, the mental health of male youth is enhanced at the expense of female youth. Moreover, to the extent that male youth were more likely than female youth to identify gender-discriminatory practices within households, but less likely than female youth to see these arrangements as inequitable makes clear that there remain formidable obstacles to improving the status of women in Indian society. Until both men and women see these arrangements as unjust, it is unlikely that gender inequalities will disappear in the short term.

\section{Conflict of Interests}

The authors declare that there is no conflict of interests regarding the publication of this paper.

\section{Acknowledgments}

An earlier version of the paper was presented at the " $22 \mathrm{nd}$ Biennial Meeting of the International Society for the Study of Behavioural Development (ISSBD 2012) during 8-12 July, 2012, in Edmonton, Alberta, Canada, and the authors are thankful to the participants for their feedback and suggestions. The David and Lucile Packard Foundation and the John D. and Catherine T. MacArthur Foundation supported the "Youth in India: Situation and Needs Study." Usual disclaimer applies.

\section{References}

[1] WHO, Women and Health: Today's Evidence, Tomorrow's Agenda, World Health Organization, Geneva, Switzerland, 2009.

[2] N. E. Moss, "Gender equity and socioeconomic inequality: a framework for the patterning of women's health," Social Science and Medicine, vol. 54, no. 5, pp. 649-661, 2002.

[3] C. West and D. H. Zimmerman, "Accounting for doing gender," Gender and Society, vol. 23, no. 1, pp. 112-122, 2009.

[4] U. Ram, P. Jha, F. Ram et al., "Neonatal, 1-59 month, and under5 mortality in 597 Indian districts, 2001 to 2012: estimates from national demographic and mortality surveys," The Lancet Global Health, vol. 1, pp. 219-226, 2013.

[5] M. Das Gupta, "Life course perspectives on women's autonomy and health outcomes," Health Transition Review, vol. 6, pp. 213231, 1996.
[6] S. L. Martina, K. E. Moracco, J. Garro et al., "Domestic violence across generations: findings from northern India," International Journal of Epidemiology, vol. 31, no. 3, pp. 560-572, 2002.

[7] L. I. Pearlin, “The sociological study of stress," in The Sociology of Mental Illness: A Comprehensive Reader, D. McLeod Jane and R. Eric Wright, Eds., Oxford University Press, New York, NY, USA, 2010.

[8] E. M. Cummings, "Marital conflict and children's functioning," Social Development, vol. 3, pp. 16-36, 1994.

[9] H. A. Turner and D. Finkelhor, "Corporal punishment as a stressor among youth," Journal of Marriage and Family, vol. 58, no. 1, pp. 155-166, 1996.

[10] A. C. Fernandes, R. D. Hayes, and V. Patel, "Abuse and other common correlates of mental disorders in youth: a crosssectional study in Goa, India," Social Psychiatry and Psychiatric Epidemiology, vol. 48, pp. 515-523, 2013.

[11] A. Pillai, T. Andrews, and V. Patel, "Violence, psychological distress and the risk of suicidal behaviour in young people in India," International Journal of Epidemiology, vol. 38, no. 2, pp. 459-469, 2009.

[12] International Institute for Population Sciences (IIPS) and Population Council, Youth in India: Situation and Needs Study 20062007, IIPS, Mumbai, India, 2010.

[13] D. Goldberg and P. Williams, A User's Guide to the General Health Questionnaire, Nfer-Nelson, Windsor, UK, 1988.

[14] D. Goldberg, General Health Questionnaire (GHQ-12), NferNelson, Windsor, UK, 1992.

[15] International Institute for Population Sciences (IIPS) and Johns Hopkins University, Quality of Care in Indian Family Planning Programme and Reproductive Behavior of Women in Four Indian States: A Follow-Up Study of NFHS 2, IIPS, Mumbai, India, 2005.

[16] V. Patel and G. Andrew, "Gender, sexual abuse and risk behaviours in adolescents: a cross-sectional survey in schools in Goa," National Medical Journal of India, vol. 14, no. 5, pp. $263-$ 267, 2001.

[17] V. Patel, R. Araya, N. Chowdhary et al., "Detecting common mental disorders in primary care in India: a comparison of five screening questionnaires," Psychological Medicine, vol. 38, no. 2 , pp. 221-228, 2008.

[18] R. Shidhaye and V. Patel, "Association of socio-economic, gender and health factors with common mental disorders in women: a population-based study of 5703 married rural women in India," International Journal of Epidemiology, vol. 39, no. 6, pp. 1510-1521, 2010.

[19] J. Mirowsky and C. E. Ross, "Measurement for a human science," Journal of Health and Social Behavior, vol. 43, no. 2, pp. 152-170, 2002.

[20] A. Pillai, V. Patel, P. Cardozo, R. Goodman, H. A. Weiss, and G. Andrew, "Non-traditional lifestyles and prevalence of mental disorders in adolescents in Goa, India," British Journal of Psychiatry, vol. 192, no. 1, pp. 45-51, 2008.

[21] C. Lund, A. Breen, A. J. Flisher et al., "Poverty and common mental disorders in low and middle income countries: a systematic review," Social Science and Medicine, vol. 71, no. 3, pp. 517-528, 2010.

[22] S. K. Khandelwal, H. P. Jhingan, S. Ramesh, R. K. Gupta, and V. K. Srivastava, "India mental health country profile," International Review of Psychiatry, vol. 16, no. 1-2, pp. 126-141, 2004 . 
[23] R. S. Murthy, "Mental health initiatives in India (1947-2010)," National Medical Journal of India, vol. 24, no. 2, pp. 98-107, 2011.

[24] S. M. McHale, A. C. Crouter, and S. D. Whiteman, "The family contexts of gender development in childhood and adolescence," Social Development, vol. 12, no. 1, pp. 125-148, 2003. 

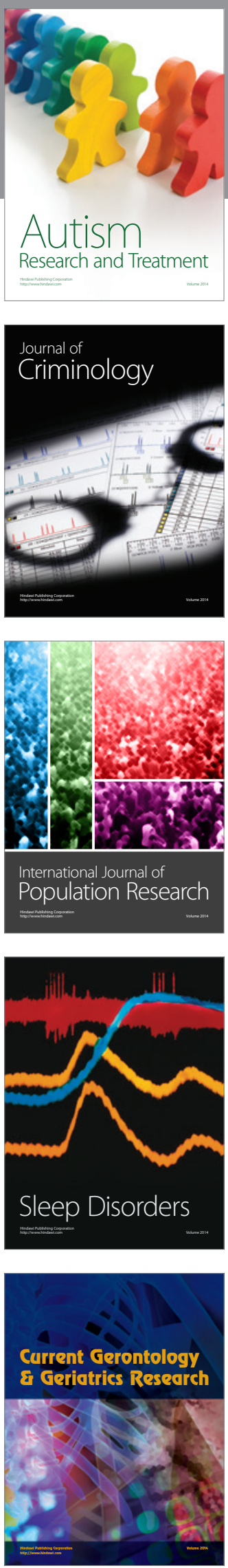
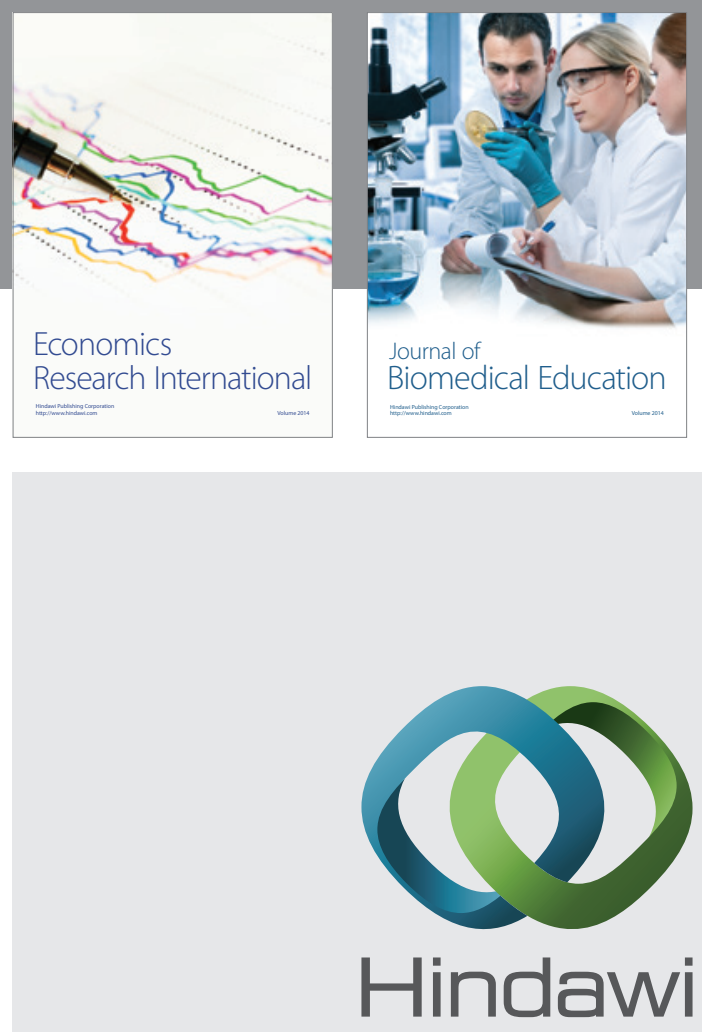

Submit your manuscripts at

http://www.hindawi.com
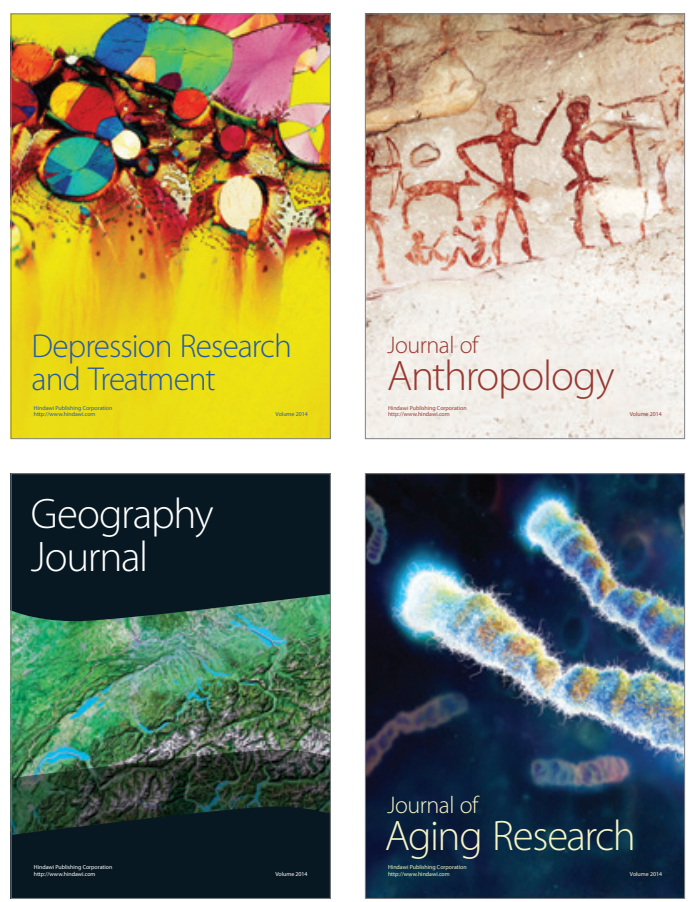
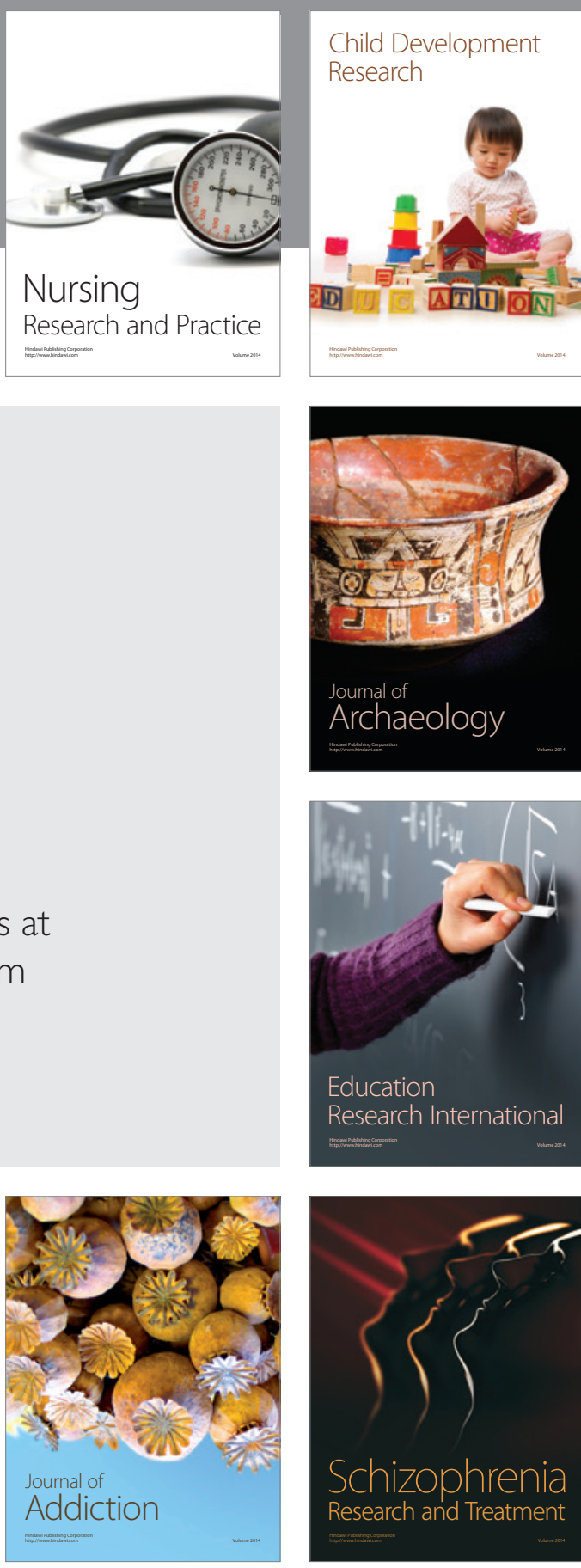

(D)
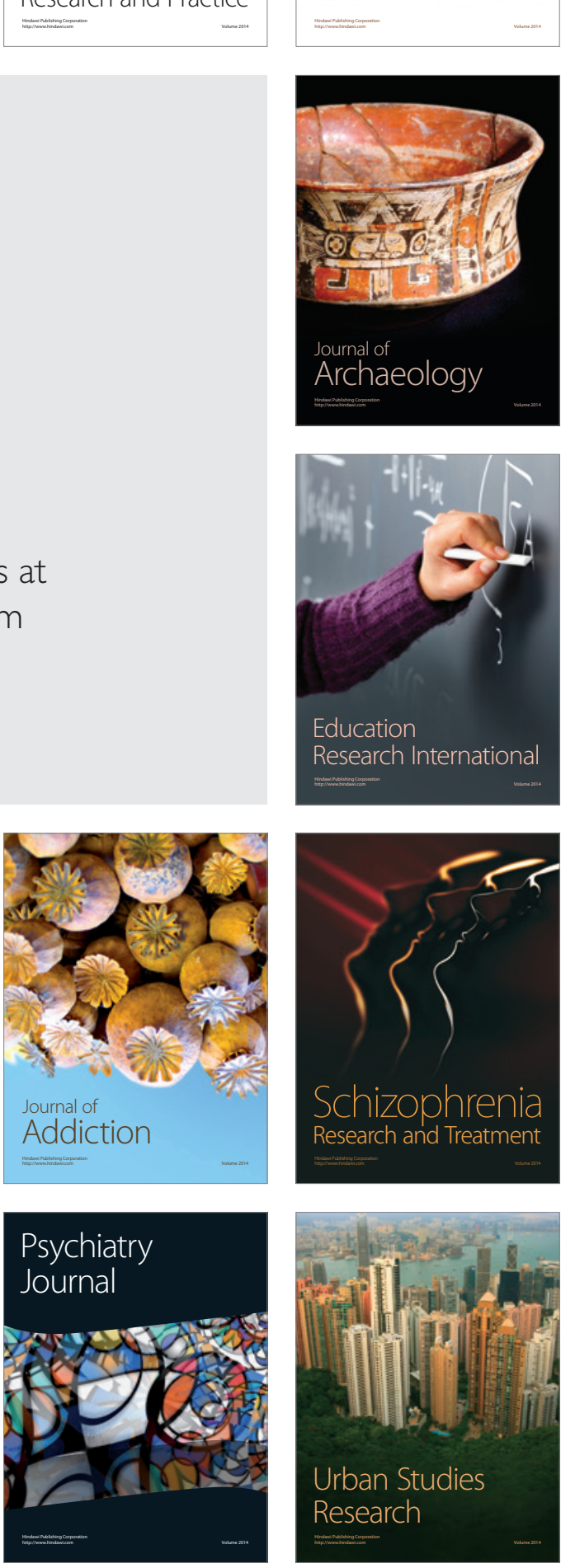